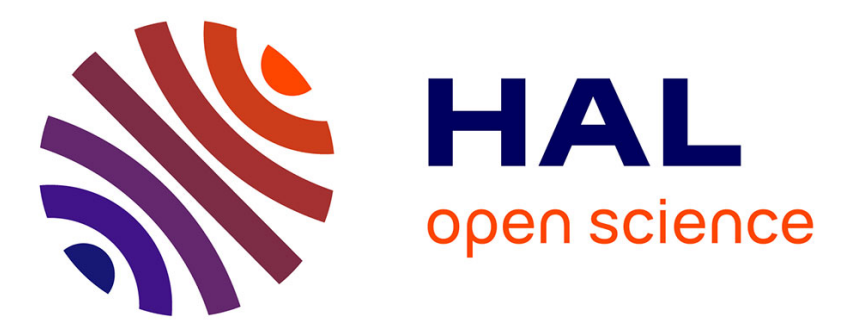

\title{
Optimal Sizing of Energy Storage Systems for Industrial Production Plants
}

\author{
Simone Zanoni, Beatrice Marchi
}

\section{To cite this version:}

Simone Zanoni, Beatrice Marchi. Optimal Sizing of Energy Storage Systems for Industrial Production Plants. IFIP International Conference on Advances in Production Management Systems (APMS), Sep 2014, Ajaccio, France. pp.342-350, 10.1007/978-3-662-44736-9_42 . hal-01387893

\section{HAL Id: hal-01387893 https://hal.inria.fr/hal-01387893}

Submitted on 26 Oct 2016

HAL is a multi-disciplinary open access archive for the deposit and dissemination of scientific research documents, whether they are published or not. The documents may come from teaching and research institutions in France or abroad, or from public or private research centers.
L'archive ouverte pluridisciplinaire HAL, est destinée au dépôt et à la diffusion de documents scientifiques de niveau recherche, publiés ou non, émanant des établissements d'enseignement et de recherche français ou étrangers, des laboratoires publics ou privés.

\section{(c)(1)}

Distributed under a Creative Commons Attribution| 4.0 International License 


\title{
Optimal sizing of Energy Storage Systems for industrial production plants
}

\author{
S. Zanoni, B. Marchi \\ Dipartimento di Ingegneria Meccanica e Industriale, Università degli Studi di Brescia \\ e-mail: simone.zanoni@unibs.it -b.marchi@unibs.it \\ via Branze, 38 - 25123 - Brescia (Italy)
}

\begin{abstract}
Most developed countries around the world are seriously concerned about recent global warming, the depletion of fossil fuels and environmental degradation. So as to meet the environmental burden reduction targets set by different international agreements, manufacturing companies are seriously encouraged to invest considerable efforts in the field of energy. Energy storage systems (ESS) have the potential to revolutionize the way in which electrical power grids are designed and operated. Presently, power grids require that the generation of electricity continuously balance the demand. The constant balancing of supply and demand has significant operational and cost implications. Incorporation of storage devices into the grid should reduce this constraint by enabling electrical energy to be withdrawn from the grid when there is excess generation and held in reserve until needed. In this work we consider stationary applications with medium discharge time (minutes to hours), thus batteries have been considered. The object is to find the optimal sizing of the energy storage device (i.e. batteries) with which it is possible to minimize the cost of energy in a production plant.
\end{abstract}

Keywords: Energy storage systems, renewable energy sources, batteries.

\section{Introduction}

Most developed countries around the world are seriously concerned about recent global warming, the depletion of fossil fuels and environmental degradation. Accordingly, effective energy use and reduction of greenhouse gas (GHG) emissions are becoming increasingly important goals. The development and use of renewable energy sources (RES) has experienced rapid growth over the past few years and, in the next 20-30 years, all sustainable energy systems will have to be based on the rational use of traditional resources and greater use of renewable energy [1]. One of the main characteristics of most of the RES is the variability in the energy production, generally linked to environmental conditions, often disjointed from real necessity of energy from users. Valuable energy produced by RES can be effectively used by storing surplus energy in a storage device and using it when required; in this way RES can be used to aid the transition for a newer and cleaner energy generation technology [2].

The main characteristics of electricity is that ideally it must be used at the same time and in the same place as it is generated. The proper amount of electricity must always be provided to meet the varying demand, and an imbalance will damage the 
stability and quality (voltage and frequency) of the power supply even when it does not lead to totally unsatisfied demand. The issues caused by these characteristics are:

- High generation cost during peak-demand periods;

- Need for continuous and flexible supply to meet changing power consumption, relying on an accurate forecast of the variations in demand;

- Needs for a more efficient grid: in order to avoid congestions, interruptions in the supply ...

In the last years, the concept of self-consumption has become increasingly relevant thanks to the many benefits that introduces in terms of energy efficiency. The use of ESS leads to a growth of the rate of energy self-consumed and improves the utilization of the PV system. For that reason, in this paper we will analyse the affordability of energy storage for an industrial plant. We consider the scenario in which a PV system is integrated with an ESS. The analysis made leads to relevant considerations on the barriers and opportunities on the use of energy storage devices.

The paper will be structured as follow: in Section 2 is presented a literature review on the ESSs; in Section 3 it is shown the proposed model and the results of the analysis and, finally, in Section 4 the concluding remarks are presented.

\section{Energy Storage System}

ESS refers to a process of converting electrical energy from a power grid into a form that can be stored for converting back to electrical energy when needed [3]. ESSs have the potential to revolutionize the way in which electrical power grids are designed and operated. Presently, power grids require the constant balancing of supply and demand and it has significant operational and cost implications. Incorporation of storage devices into the grid would relax this constraint by enabling electrical energy to be withdrawn from the grid when there is excess generation and held in reserve until needed [4]. ESS is expected to play an important role thanks to the rapidly accelerating rate of technological development with anticipated unit cost reductions [3] (Figure 2).

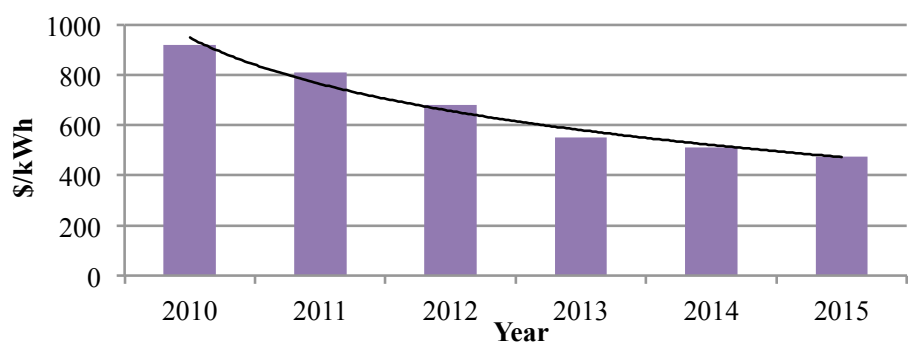

Figure 1. Lithium Ion Battery Price per kWh

From the viewpoint of consumers, the main roles of ESS are:

Time shifting and cost savings by using ESS to reduce peak power and to purchase electricity at off-peak times;

- $\quad$ Emergency power supply to operate during an outage. 
There are two major emerging market needs for ESS as a key technology: to utilize more renewable energy and less fossil fuel, and the future Smart Grid. The increased ratio of RES generation may cause several issues in the power grid. First, the fluctuation in the output of RES generation makes system frequency control difficult. Secondly, RES output is undependable since it is affected by weather conditions, and any surplus power may be thrown away when not needed on the demand side (see Figure 3). ESS may intervene against those issues, stabilizing RES output, increasing self-consumption and through time shifting (i.e. matching the supply and demand of energy). Therefore valuable energy can be effectively used by storing surplus electricity in ESS and using it when necessary and it can also be sold when the price is high (i.e. generation shifting scenario). As is said in [5], the generation shifting scenario is expected to be the first widespread application of ESSs as it is the one that may potentially generate additional revenues in a PV project.

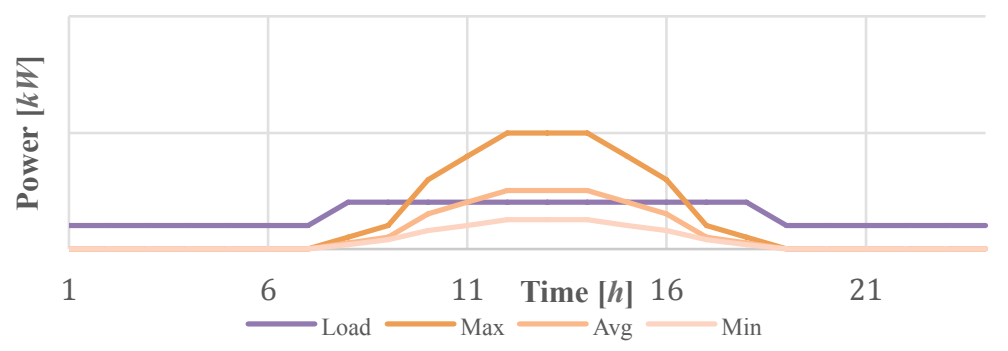

Figure 2. Energy consumption and PV production

ESSs can be characterized in terms of: energy and power capacity, round trip efficiency, response time, discharge duration, discharge frequency, depth of discharge and self-discharge. A complete definition of those characteristics can be found in [4]. A widely-used approach for classifying ESS systems is the determination according to the form of energy used: mechanical, electrochemical, chemical, electrical and thermal ESSs [6]. Different applications with different requirements demand different features form electrical ESS. In this paper we consider stationary applications with medium discharge time (minutes to hours), in which electrochemical ESS (i.e. batteries) - for larger capacities - and flywheel energy storage (FES) are the dominant technology. Rechargeable/secondary battery is the oldest form of electricity storage. As is said in [7], batteries are devices that convert chemical energy into electrical energy, by oxidation and reduction of their materials. The details of various types of batteries have been discussed in numerously paper - [1] - [3] and [8]. Batteries are in some ways ideally suited for electrical energy storage applications because they provide fuel flexibility and environmental benefits, they can respond very rapidly to load changes and enhance the system stability. Batteries usually have very low standby losses and can have high energy efficiency. The construction of a secondary battery is facilitated by the short lead times and the technology's modularity. However, battery storage has some disadvantages too: low energy densities, small power capacity, high maintenance costs, a short cycle life a limited discharge capability and most batteries contain toxic materials. Hence the ecological impact from uncontrolled disposal of batteries must always be considered [3]. Some of the most used technologies are: 
Lead Acid, Sodium Sulphide (NaS) and Lithium Ion (Li-Ion) Batteries. In Table 1, are shown the main characteristics from literature of the mentioned batteries:

Table 1. Batteries' Characteristics

\begin{tabular}{cccc}
\hline & Lead Acid & NaS & Li-Ion \\
\hline Cost [€/kWh] & 150 & 250 & 1000 \\
Round Trip Efficiency [\%] & 80 & 89 & 98 \\
Life [cycle] & 2000 & 2500 & 4000 \\
Life [years] & 12 & 15 & 20 \\
DOD [\%] & 80 & 100 & 80 \\
Self-Discharge [\%/month] & 5 & 0 & 1 \\
\hline
\end{tabular}

\section{The Model}

The object of this work is to analyze the scenario in Figure 5, in order to find the optimal sizing of the energy storage device (i.e. batteries) with which it is possible to minimize the cost of energy management and purchase in an industrial system.

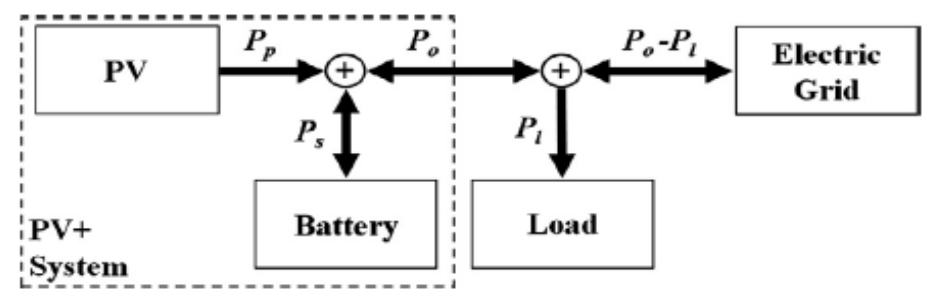

Figure 3. Reference scheme of the PV+ESS system [9]

The main notation used is given in the following table:

Table 2. Main Notation

\begin{tabular}{|c|c|c|c|}
\hline$p_{e, t}$ & $\begin{array}{l}\text { Unit price to sell a } \mathrm{kWh} \text { to the grid in } \mathrm{t} \\
{[€ / \mathrm{kW} \mathrm{h}]}\end{array}$ & $E_{\text {stored,t }}$ & $\begin{array}{l}\text { Energy stored at the beginning of } t \\
{[\mathrm{~kW} \mathrm{~h}]}\end{array}$ \\
\hline$p_{\text {self }, t}$ & $\begin{array}{l}\text { Unit premium price to self-consume a } \\
\mathrm{kWh} \text { of renewable energy produced in } \mathrm{t} \\
{[€ / \mathrm{kW} h]}\end{array}$ & $E_{\text {losses, } t}$ & $\begin{array}{l}\text { Energy loss in t due to the charac- } \\
\text { teristics of the battery [kW h] }\end{array}$ \\
\hline$c_{e, t}$ & $\begin{array}{l}\text { Unit cost to buy a } \mathrm{kWh} \text { from the grid in } \\
\mathrm{t}[€ / \mathrm{kW} \mathrm{h}]\end{array}$ & $P_{c, t}$ & $\begin{array}{l}\text { Charging power from the grid in } \mathrm{t} \\
{[\mathrm{kW}]}\end{array}$ \\
\hline$D_{t}$ & Energy demand in $\mathrm{t}[\mathrm{kW} \mathrm{h}]$ & $P_{d, t}$ & $\begin{array}{l}\text { Discharging power from the de- } \\
\text { vice in } t[\mathrm{~kW}]\end{array}$ \\
\hline$P_{t}$ & Energy production in $\mathrm{t}[\mathrm{kW} \mathrm{h}]$ & $E_{\max }$ & $\begin{array}{l}\text { Device's energy capacity - i.e. } \\
\text { maximum energy the device can } \\
\text { store }[\mathrm{kW} \text { h] }\end{array}$ \\
\hline$E_{\text {grid }, t}$ & Energy taken from the grid in $\mathrm{t}[\mathrm{kW} \mathrm{h}]$ & $P_{\max }$ & $\begin{array}{l}\text { Device's power capacity }- \text { i.e. } \\
\text { maximum charge or discharge rate } \\
{[\mathrm{kW}]}\end{array}$ \\
\hline
\end{tabular}




\begin{tabular}{|c|c|c|c|}
\hline$E_{\text {sold }, t}$ & Energy sold to the grid in $\mathrm{t}[\mathrm{kW} \mathrm{h}]$ & $P_{\text {nom }}$ & $\begin{array}{l}\text { Device's nominal power capacity } \\
{[\mathrm{kW}]}\end{array}$ \\
\hline$E_{\text {self }, t}$ & $\begin{array}{l}\text { Renewable energy self-consumed in } \mathrm{t} \\
{[\mathrm{kW} \mathrm{h}]}\end{array}$ & $D O D$ & Depth of discharge [\%] \\
\hline$\alpha$ & Battery's cost reduction & $C_{B E S S}$ & $\begin{array}{l}\text { Total cost of the energy storage } \\
\text { device }[€ / \text { year }]\end{array}$ \\
\hline$L_{B E S S}$ & Batteries' lifetime [years] & $t$ & Hourly time interval $[\mathrm{h}]$ \\
\hline$\rho$ & Discount rate $[\%]$ & $N$ & $\begin{array}{l}\text { Time interval for BESS investment } \\
\text { [years] }\end{array}$ \\
\hline
\end{tabular}

The model consists in the minimization of the total annual cost of energy (i.e. cost for the energy purchased from the grid and costs due to the investment and use of BESS):

$$
\min T C\left(P_{\text {nom }}\right)=\sum_{t=1}^{8760}\left(c_{e, t} \cdot E_{\text {grid }, t}\left(P_{\text {nom }}\right)-p_{e, t} \cdot E_{\text {sold }, t}\left(P_{\text {nom }}\right)-p_{\text {self }, t} \cdot E_{\text {self }, t}\left(P_{\text {nom }}\right)\right)+C_{\text {BESS }}\left(P_{\text {nom }}\right)
$$

where

$$
\begin{aligned}
P_{\max }=P_{n o m} \cdot & D O D \\
C_{B E S S}\left(P_{n o m}\right) & =\frac{C_{B E S S, 0}\left(P_{n o m}\right)+\sum_{i} \frac{C_{B E S S, i}\left(P_{n o m}\right)}{(1+\rho)^{i}}}{n} \\
& \text { with } i=L_{B E S S}, 2 \cdot L_{B E S S}, . ., N-L_{B E S S}, \quad i>0 \\
C_{B E S S, i}\left(P_{n o m}\right) & =C_{B E S S, 0}\left(P_{n o m}\right)-\alpha \cdot \ln (i)
\end{aligned}
$$

The constraints of the model are following reported:

$$
\begin{aligned}
& D_{t}+E_{\text {sold }, t}\left(P_{\text {nom }}\right)=P_{t}+E_{\text {grid }, t}\left(P_{\text {nom }}\right)-E_{\text {losses }, t}\left(P_{\text {nom }}\right) \\
& 0 \leq P_{d, t}\left(P_{\text {nom }}\right), P_{c, t}\left(P_{\text {nom }}\right) \leq P_{\max }\left(P_{\text {nom }}\right) \\
& 0 \leq E_{\text {stored }, t}\left(P_{\text {nom }}\right) \leq E_{\max }\left(P_{\text {nom }}\right)
\end{aligned}
$$

Due to the presence of several key technologies of electrochemical storage, it has been decided to compare different scenario considering the three types of batteries mentioned in the previous section. The proposed model guarantees that the hourly demand of the production plant is met by the joint action of the energy generation of the PV system and the energy stored in the batteries. The connection to the power grid serves as a backup resource, if the production from RES is not sufficient to cope with the demands.

The data used in the implementation of the model are referred to an industrial plant in Italy already equipped with a photovoltaic system (PV), whose profiles of demand and PV production are shown in Figure 6. For the electricity cost and incentives it has been considered the regulatory framework of the country. 


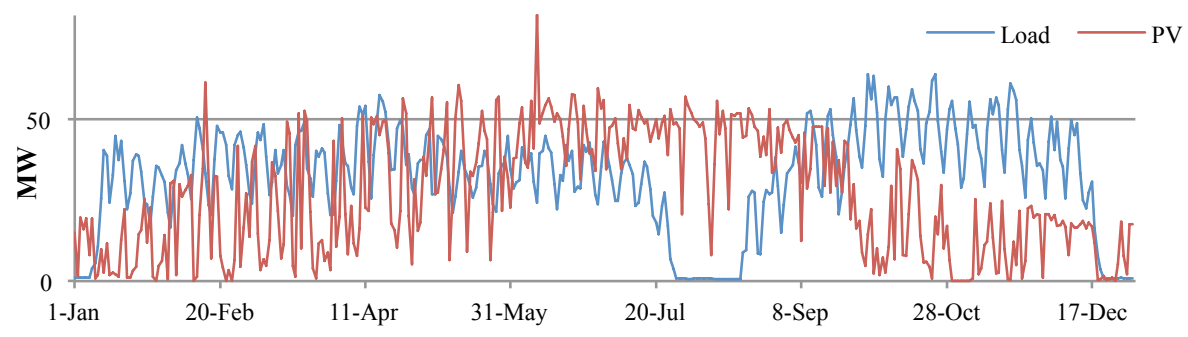

Figure 4. Demand and PV Production patterns over a year

In addition to the total cost, it is interesting to observe how the values of the following indexes change: self-consumption (share of the energy produced that is selfconsumed without being fed into the grid) and self-sufficiency (share of total energy demand that is satisfied with that produced by the PV system).

Table 3 shows the results of the model:

Table 3. Model's Results

\begin{tabular}{|c|c|c|c|c|c|}
\hline & & \multirow[t]{2}{*}{ PV } & \multicolumn{3}{|c|}{ PV+BESS } \\
\hline & & & Lead Acid & $\mathrm{NaS}$ & Li-Ion \\
\hline $\mathbf{P}_{\text {nom }}^{*}$ & [MW] & 0 & 3,83 & 4,21 & 0 \\
\hline TC & {$[€ /$ year $]$} & $1.351 .550,12$ & $1.323 .523,91$ & $1.306 .654,44$ & $1.351 .550,12$ \\
\hline Self-Consumption & {$[\%]$} & $36 \%$ & $44 \%$ & $44 \%$ & $36 \%$ \\
\hline Self-Sufficiency & {$[\%]$} & $30 \%$ & $36 \%$ & $37 \%$ & $30 \%$ \\
\hline
\end{tabular}

In Figure 7, it is possible to observe the benefits and costs introduced with BESS. As it can be seen, the use of new more performing technologies (Li-Ion) is replaced by mature technologies because of the cost of investment still too high. When the investment in storage technologies is profitable, we attend an increase of both the indices (i.e. self-consumption and self-sufficiency). See Table 3.

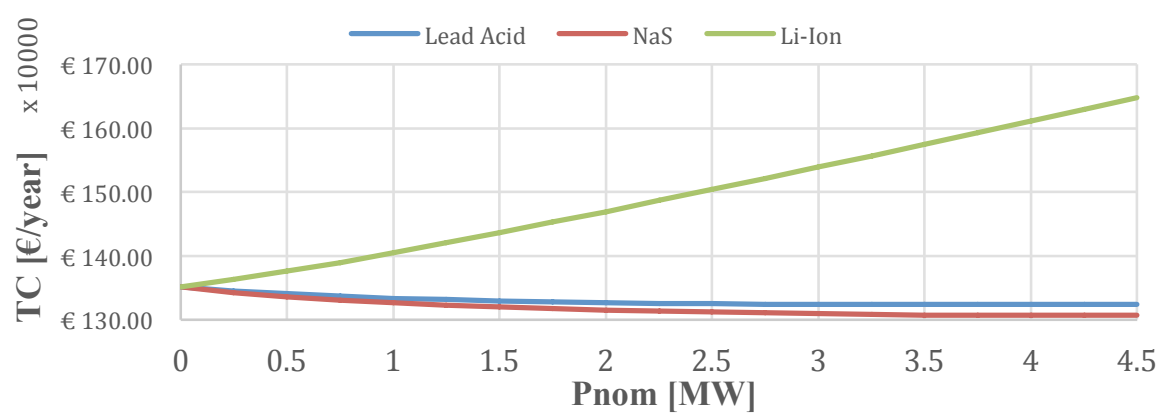

Figure 5. Total annual energy cost varying the nominal power of the BESS

Other interesting observations are: 
- Lower financial incentives (or even higher energy cost) leads to an increased installed power (Figure 8a);

- Total costs are very sensible to the cost of the batteries; thus, with a low reduction of the battery's capital cost it is possible to obtain a great increase of the benefits (Figure $8 \mathrm{~b}$ ). Even Li-Ion batteries become affordable, when their cost is at least halved.
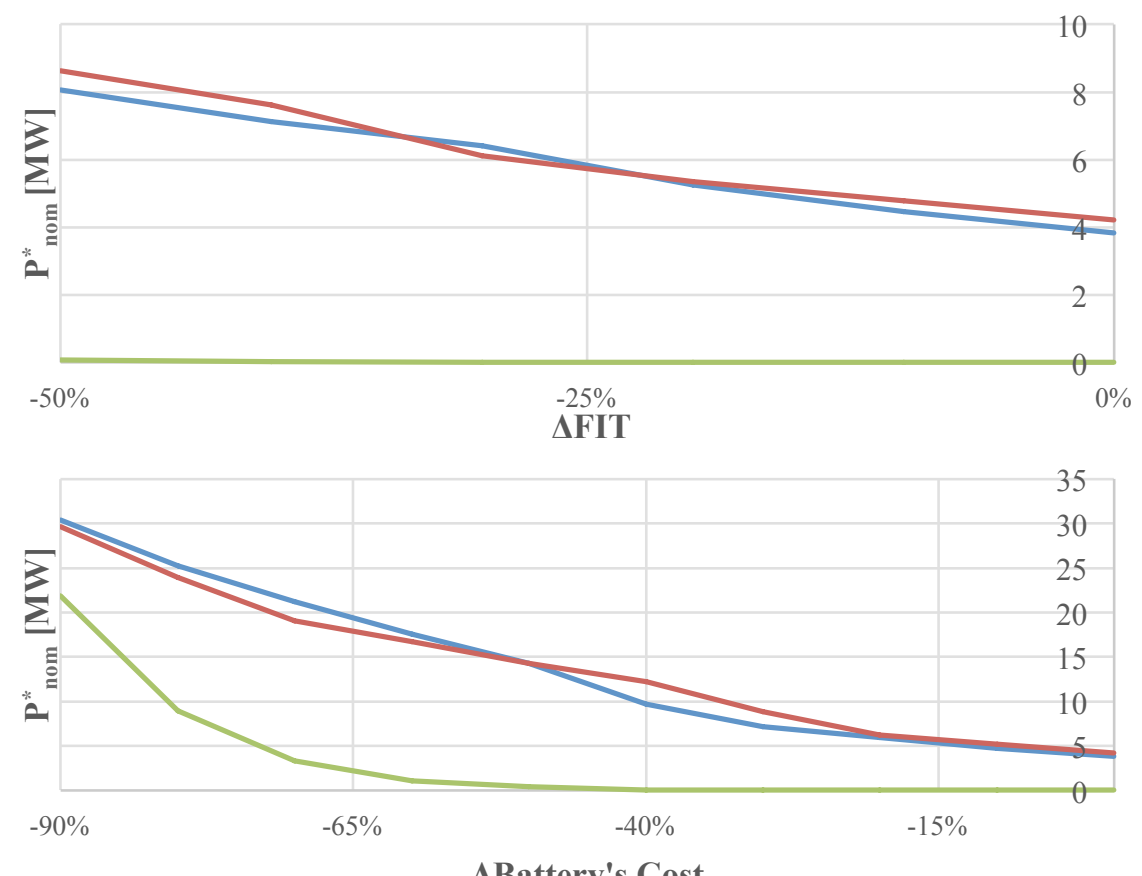

$\Delta$ Battery's Cost

Figure 6. Sensitivity analysis: (a) reduction of Financial Incentives and (b) the Batteries' Cost

\section{Conclusions}

ESSs is a recent and relevant topic in energy efficiency, as they may help to overcome the intermittency of RES and they may also be used to shift electricity to times when it costs less. Thus, it will be very interesting and useful to consider its impact in a production plant, already equipped with a PV system.

This work is one of the first attempt to depict the problem of affordability of the integrated system PV+ESS. Similar analysis has never been yet considered in the industrial context: actually, does exist only some studies on the domestic storage.

In the present work an analytical model has been developed so as to perform an economic analysis of the problem presented, in order to analyse the economic convenience of an investment in energy storage devices. From this point of view the analysis is strongly affected by the country and year considered (due to the incentive framework). From the analysis carried out, it can be concluded that the economic benefit introduced through the use of BESS and due to the increase of plant's selfconsumption is highly dependent on the type of battery used, and most importantly, 
on its cost of investment. In the specific case considered, it is possible to observe that Lead Acid and Sodium Sulphide batteries results convenient while, on the contrary, the most efficient Lithium-Ion batteries are still too expensive. Given the recent advances in technology, in the next few years, it is expected a trend characterized by a significant reduction in the investment cost that will make the same Lithium-Ion battery affordable: i.e. able to generate economic benefits greater than the costs introduced in the system.

Finally it should be noted that the analysis included here, if properly adjusted, could be applied to any kind of production plants, ESS (e.g. batteries, supercapacitors, ...) and energy system (e.g. wind power, biomass or biogas systems).

\section{References}

[1] H. Ibrahim, a Ilinca, and J. Perron, "Energy storage systems - Characteristics and comparisons," Renew. Sustain. Energy Rev., vol. 12, no. 5, pp. 12211250, Jun. 2008.

[2] T. M. I. Mahlia, T. J. Saktisahdan, a. Jannifar, M. H. Hasan, and H. S. C. Matseelar, "A review of available methods and development on energy storage; technology update," Renew. Sustain. Energy Rev., vol. 33, pp. 532545, May 2014.

[3] H. Chen, T. N. Cong, W. Yang, C. Tan, Y. Li, and Y. Ding, "Progress in electrical energy storage system: A critical review," Prog. Nat. Sci., vol. 19, no. 3, pp. 291-312, Mar. 2009.

[4] K. Bradbury, L. Pratson, and D. Patiño-Echeverri, "Economic viability of energy storage systems based on price arbitrage potential in real-time U.S. electricity markets," Appl. Energy, vol. 114, pp. 512-519, Feb. 2014.

[5] V. Rudolf and K. D. Papastergiou, "Financial analysis of utility scale photovoltaic plants with battery energy storage," Energy Policy, vol. 63, pp. 139-146, Dec. 2013.

[6] (IEC) International Electrotechnical Commission, "Electrical Energy Storage," no. December, 2011.

[7] J. I. San Martín, I. Zamora, J. Aperribay, J. J. San Martín, and P. Eguía, "Energy Storage Technologies for Electric Applications," in International Conference on Renewable Energies and Power Quality, 2011, no. 2.

[8] K. C. Divya and J. Østergaard, "Battery energy storage technology for power systems-An overview," Electr. Power Syst. Res., vol. 79, no. 4, pp. 511520, Apr. 2009.

[9] R. Hanna, J. Kleissl, a. Nottrott, and M. Ferry, "Energy dispatch schedule optimization for demand charge reduction using a photovoltaic-battery storage system with solar forecasting," Sol. Energy, vol. 103, pp. 269-287, May 2014. 